\title{
Coccomyxa Gloeobotrydiformis Polysaccharide Inhibits Lipopolysaccharide- Induced Inflammation in RAW 264.7 Macrophages
}

\author{
Bo Dai ${ }^{a}$ Dan Wei ${ }^{a} \quad N i n g-n i n g ~ Z h e n{ }^{a}$ Zhi-hong Chi ${ }^{a}$ Na Xin ${ }^{a} \quad$ Ting-xian Ma \\ Lan-yan Zheng $^{b}$ Ryo Sumic Luning Sun ${ }^{a}$ \\ aDepartment of Pathophysiology, College of Basic Medical Science, China Medical University, \\ Shenyang, ${ }^{b}$ Department of Microbiology and Parasitology, College of Basic Medical Science, China \\ Medical University, Shenyang, China, 'Tanaka Memorial Laboratory, Nikken Sohonsha Corporation, \\ Gifu, Japan
}

\section{Key Words}

Coccomyxa Gloeobotrydiformis Polysaccharide • Inflammation • Noncommunicable Diseases - Cytokines • Cell Signaling Pathways

\begin{abstract}
Background/Aims: Inflammation plays a vital role in the etiology and pathogenesis of chronic noncommunicable diseases (NCDs), which are the leading health issues throughout the world. Our previous studies verified the satisfactory therapeutic effects of Coccomyxa gloeobotrydiformis (CGD) polysaccharide on several NCDs. In this study, we aimed to investigate the anti-inflammatory effects of CGD polysaccharide, and the corresponding molecular mechanisms, on lipopolysaccharide (LPS)-induced inflammation in RAW264.7 cells. Methods: A viability assay and a lactate dehydrogenase (LDH) assay were used to measure the cytotoxic effects of CGD polysaccharide on LPS-stimulated RAW264.7 cells. To investigate the potential anti-inflammatory mechanisms of CGD polysaccharide in LPS-stimulated RAW264.7 cells, nitric oxide (NO) production was determined using a NO assay and the expression of inflammatory mediators (PGE ${ }_{2}$ iNOS and COX-2), inflammatory cytokines (TNF- $\alpha, I L-6, I L-1 \beta$ and IL-10) and inflammation-related signaling pathways (the MAPK/NF-KB, PI3K/AKT/JNK, JAK/STAT and $\mathrm{Nrf2/HO}-1$ pathways) were observed by western blotting. The translocation of NF- $\mathrm{kB}$ p65 was also observed using an immunofluorescent assay. Results: CGD polysaccharide significantly

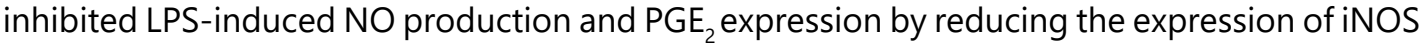
and COX-2. It also suppressed the expression of the pro-inflammatory cytokines TNF- $\alpha$, IL- 6 and IL-1 $\beta$, and up-regulated the expression of the anti-inflammatory cytokine IL-10. Further experiments demonstrated that CGD polysaccharide could inhibit inflammatory signaling pathways (the MAPK/NF-KB, PI3K/AKT/JNK and JAK/STAT pathways). At the same time, it
\end{abstract}




\section{Cellular Physiology Cell Physiol Biochem 2018;51:2523-2535

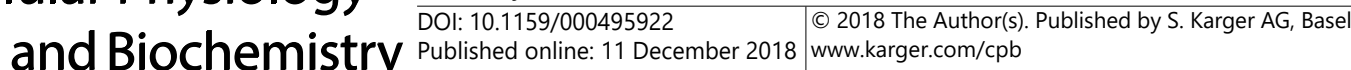 \\ Dai et al.: CGD Inhibits LPS-Induced Inflammation via Regulating the Signaling \\ Pathways}

enhanced the anti-inflammatory pathway Nrf2/HO-1. In addition, CGD polysaccharide did not display any cytotoxic effects, even at a high concentration. Conclusion: Taken together, the results suggest that CGD polysaccharide significantly inhibits LPS-induced inflammation in RAW264.7 cells. This effect lies in its regulatory effects on the signaling pathways MAPK/ NF-KB, PI3K/AKT/JNK, JAK/STAT and Nrf2/HO-1.Our findings reveal that CGD polysaccharide has the potential to be used as a relatively safe and effective drug as part of the treatment of NCDs.

\section{Introduction}

Inflammation is an extremely complex process composed of different and complementary phases that involves inflammatory mediators, inflammatory cytokines and inflammationrelated signaling pathways [1]. A moderate and reasonable inflammatory response can help to clear away injurious material or agents and to promote tissue repair, while an excessive or deregulated inflammatory response may result in lack of restoration of tissue health and induction of a chronic condition. This can directly and/or indirectly promote the occurrence and progression of certain noncommunicable diseases (NCDs) [2]. In recent years, NCDs such as diabetes mellitus, coronary artery disease and cancers have become leading health issues throughout the world. An anti-inflammatory agent may be an important treatment for these diseases. Although a large number of synthetic anti-inflammatory compounds have been developed during the past decades, most of them have detrimental side effects after prolonged usage $[3,4]$. Therefore, the need for anti-inflammatory drugs with higher efficacy and lower toxicity is even greater nowadays.

Marine microalgae-derived polysaccharides have been shown to have a variety of bioactivities such as anti-oxidant, anti-inflammatory and anti-tumor effects [5]. Coccomyx agloeobotrydiformis(CGD) polysaccharide is extracted from CGD, a species of green algae that is distributed in Iceland, the Himalayas, Japan, New Zealand and Antarctica [6]. In our previous studies, we observed satisfactory therapeutic effects of CGD polysaccharide on certain inflammation-related disorders, e.g., it could protect against oxidative damage in the hippocampus of a rat model of ischemic stroke [7], and it might improve the learning and memory ability of older rats by acting as an anti-inflammatory agent [8]. Recently, we found that CGD polysaccharide could also recover metabolic homeostasis and relieve cardiovascular complications in a rat model of metabolic syndrome [9]. However, the specific mechanisms, including the inflammatory signaling pathways involved, especially the major targets of CGD polysaccharide, are still unclear.

Based on the above, this study aimed to observe the anti-inflammatory effects of CGD polysaccharide in RAW264.7 macrophages. Furthermore, the molecular mechanism was investigated by focusing on the potential regulatory roles of CGD polysaccharide in several classic inflammation-related signaling pathways.

\section{Materials and Methods}

Cell culture and viability assay

RAW264.7, a mouse macrophage cell line (ATCC, USA), was cultured in high-glucose Dulbecco's modified Eagle's medium (DMEM) (Biological Industries, BeitHaemek, Israel) containing 10\% fetal bovine serum (FBS)(Clack Bioscience, USA), $100 \mathrm{U} / \mathrm{mL}$ penicillin and $100 \mu \mathrm{g} / \mathrm{mL}$ streptomycin (HyClone, Logan, UT, USA) at $37^{\circ} \mathrm{C}$ in a humidified incubator containing $5 \% \mathrm{CO}_{2}$. After overnight culture in a 96-well plate $\left(2 \times 10^{4}\right.$ cells/well, $100 \mu$ Lmedium/well), the cells were treated with CGD polysaccharide (Nikken Sohonsha Corporation, Japan) ( 2 or $4 \mathrm{mg} / \mathrm{mL}$ ) in the absence or presence of $1 \mu \mathrm{g} / \mathrm{mL}$ lipopolysaccharide (LPS) 


\section{Cellular Physiology Cell Physiol Biochem 2018;51:2523-2535

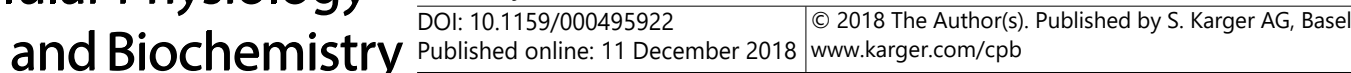 Dai et al.: CGD Inhibits LPS-Induced Inflammation via Regulating the Signaling Pathways}

(Escherichia coli 055:B5;Sigma-Aldrich, USA) for 24h. Thereafter, $20 \mu \mathrm{L}$ Cell Titer $96 \AA$ AQueous One Solution Cell Proliferation Assay (MTS) (Promega, Madison, WI, USA) solution was added to each well and incubated at $37^{\circ} \mathrm{C}$ for $3 \mathrm{~h}$. Finally, the absorbance of each well was recorded at $490 \mathrm{~nm}$ using a microplate reader (KHB ST-360; Shanghai Kehua Laboratory System, Shanghai, China).

\section{Lactate dehydrogenase ( $L D H)$ release assay}

The LDH activity was determined using a commercial LDH assay kit (Wanleibio Co., Ltd., Shenyang, China) according to the manufacturer's instructions. First, $40 \mu$ Lcell-free supernatant or cell lysate was mixed with nicotinamide-adenine dinucleotide (NADH) and 2, 4-dinitrophenylhydrazine and incubated at $37^{\circ} \mathrm{C}$ for $15 \mathrm{~min}$.Next, $0.4 \mathrm{~mol} / \mathrm{L} \mathrm{NaOH}$ was added to the samples and incubated at $37^{\circ} \mathrm{C}$ for $3 \mathrm{~min}$. Finally, the absorbance of each sample was recorded at 440nm using a UV spectrophotometer (Shimadzu Corporation, Tokyo, Japan).

\section{Nitric oxide (NO) production assay}

Based on the Griess reaction, the NO production was determined using a commercial NO assay kit (Beyotime Institute of Biotechnology, Nanjing, China) according to the manufacturer's instructions; $50 \mu \mathrm{L}$ cell culture medium and $100 \mu \mathrm{L}$ Griess reagents I and II were reacted in a 96-well plate at room temperature (RT) for $10 \mathrm{~min}$, and the absorbance was then measured at $540 \mathrm{~nm}$ using a microplate reader.

\section{Western blot analysis}

RAW 264.7 cells were harvested on ice and washed in ice-PBS after treatment, and then the cells were lysed with lysis buffer containing a cocktail of protease and phosphatase inhibitors on ice for $30 \mathrm{~min}$ to extract the total protein. Cellular cytoplasmic and nuclear proteins were obtained using a Nuclear and Cytoplasmic Protein Extraction kit (Beyotime Institute of Biotechnology), and an enhanced BCA protein assay kit (Beyotime Institute of Biotechnology) was then used to determine the protein concentrations. The protein samples were subjected to 10\% 15\% SDS-PAGE and transferred onto a PVDF membrane. After blocking with $5 \%$ skimmed milk for $2 \mathrm{~h}$ at RT, the membranes were incubated overnight at $4^{\circ} \mathrm{C}$ with their respective primary antibodies. These antibodies targeted mitogen-activated protein kinases (MAPKs), p65, p-p65, hemeoxygenase (HO)-1, nuclear factor erythroid 2-related factor 2 (Nrf2) and iNOS (1:1000;CST,USA); AKT, p-AKT, p-STAT3, COX-2, IL-1 $\beta$, TNF- $\alpha$, IL-6, IL-10, GAPDH, $\beta$-actin and $\beta$-tubulin (1:1000; CST); STAT3 and PCNA (1:300; CST); PI3K (1:500; WanleibioCo.,Ltd); and PGE2 (1:1000,Bioss,USA). The membranes were then incubated with horseradish peroxidase-conjugated secondary antibodies (1:3000; WanleibioCo.,Ltd) containing a blocking solution at RT for $1 \mathrm{~h}$. The antigen-antibody complexes were detected with an ECL detection kit (ThermoFisher Scientific, Waltham, MA, USA) according to the manufacturer's instructions.

\section{Immunofluorescent assay}

RAW264.7 cells $\left(2 \times 10^{5} /\right.$ well $)$ were cultured overnight on a 14 -mm cell slide in a 24 -well plate. The cells were treated with 2 or $4 \mathrm{mg} / \mathrm{mL}$ CGD polysaccharide for $2 \mathrm{~h}$ and then co-stimulated with LPS $(1 \mu \mathrm{g} /$ $\mathrm{mL}$ ) for $1 \mathrm{~h}$. After washing with PBS, the cells were fixed with $4 \%$ paraformaldehyde for $15 \mathrm{~min}$ at RT, and then the cells were incubated with $0.2 \%$ Triton X-100 for $10 \mathrm{~min}$. They were then washed with PBS and blocked with 5\% BSA in PBS for 30min at RT. After this, the cells were incubated with rabbit anti-NF- $\mathrm{kB}$ p65 antibody(1:200;CST) followed by FITC-conjugated goat anti-rabbit IgG(H+L)(1:50; Zhongshan Company, Beijing, China).Three washes with PBS were performed before and after antibody incubation. Finally, the fluorescence signals were analyzed by laser scanning confocal microscopy (Nikon, Tokyo, Japan).

\section{Statistical analysis}

All data from experiments are represented as the mean \pm standard error of the mean (SEM) of at least three independent experiments. Statistical analysis was performed using one-way analysis of variance (ANOVA) with Tukey's multiple comparison test. $P<0.05$ was considered to be statistically significant. 


\section{Cellular Physiology Cell Physiol Biochem 2018;51:2523-2535 and Biochemistry \begin{tabular}{c|c|c|c|} 
DOl: 10.1159/000495922 \\
Publisned 2018 The Author(s). Published by S. Karger AG, Basel
\end{tabular} Dai et al.: CGD Inhibits LPS-Induced Inflammation via Regulating the Signaling Pathways}

\section{Results}

\section{CGD polysaccharide inhibited LPS-stimulated RAW264.7 cells viability}

The inhibitory effect of CGD polysaccharide on RAW264.7cell growth was assessed using MTS assays. As shown in Fig. 1A, CGD polysaccharide significantly inhibited the viability of RAW264.7 cells and prevented LPS-induced RAW264.7 activation in a dose-dependent manner. LPS stimulates the formation of spindle-shaped pseudopodia, which is one of the signs of RAW264.7 cells activation. CGD polysaccharide reversed this process, so the cells recovered their original round shape (Fig. 1B). According to the results of LDH release assay, CGD polysaccharide did not display any cytotoxic effects (Fig. 1C).

\section{CGD polysaccharide regulated the production of inflammatory mediators in RAW264.7} cells

$\mathrm{NO}$ and $\mathrm{PGE}_{2}$ are important inflammatory mediators whose expression is regulated by iNOS and COX-2, respectively. As shown in Fig. 2A and 2B, CGD polysaccharide significantly inhibited the expression of iNOS and COX-2 in LPS-stimulated RAW264.7 cells. As a result, the NO production and $\mathrm{PGE}_{2}$ expression decreased. Under normal physiological conditions, the production of pro- and anti-inflammatory cytokines is in homeostasis. When proinflammatory cytokines overwhelm the anti-inflammatory cytokines, this balance is disturbed, which might trigger an inflammatory process. As shown in Fig. 2C, CGD polysaccharide

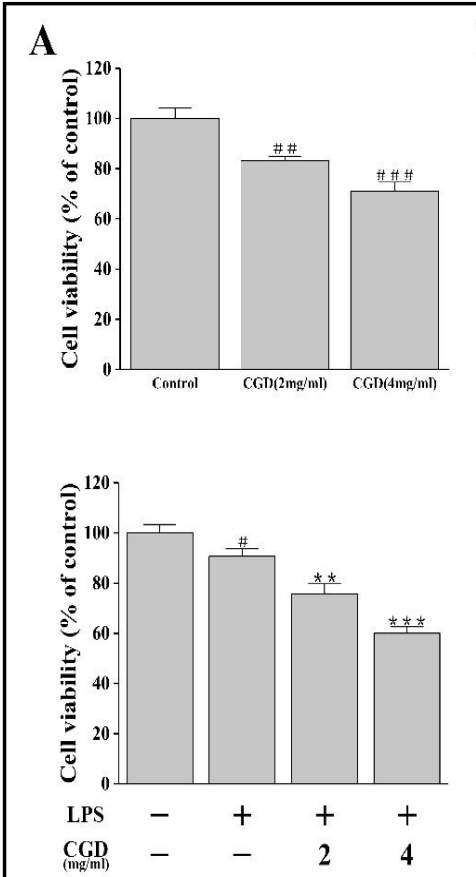

B

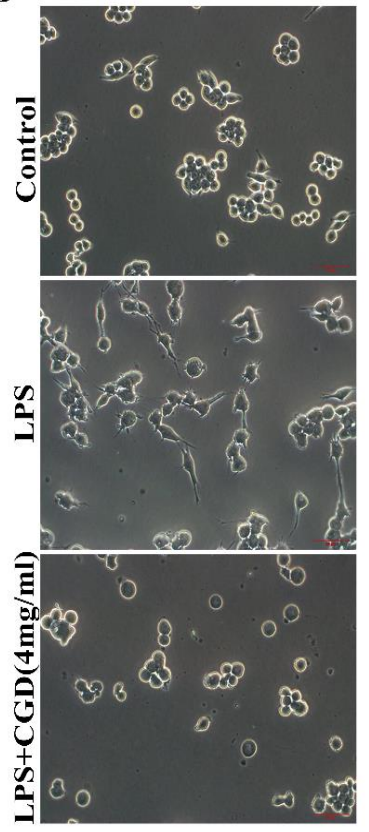

C

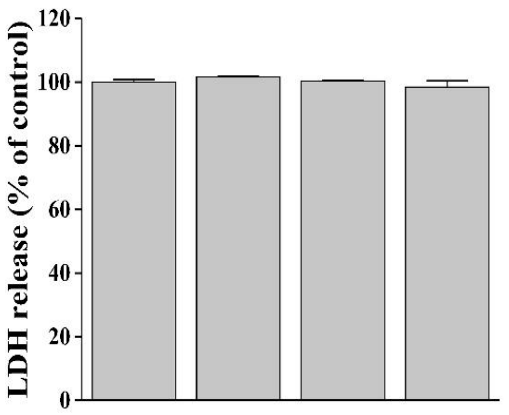

Fig. 1. The effects of CGD polysaccharide on the viability and morphology of LPS-stimulated RAW264.7 cells. The cells were treated with CGD polysaccharide ( 2 or $4 \mathrm{mg} / \mathrm{mL}$ ) for $2 \mathrm{~h}$ in the absence or presence of $1 \mu \mathrm{g} /$ mL LPS for $24 \mathrm{~h}$. (A) The cell viability of RAW264.7 cells was assessed by MTS assay, and CGD polysaccharide significantly inhibited the cell viability and partially prevented the decline in LPS-stimulated RAW264.7 viability in a dose-dependent manner. (B) The morphology of the cells was observed under inverted phase contrast microscope, and LPS stimulated the formation of the spindle-shaped pseudopodia, whereas CGD polysaccharide $(4 \mathrm{mg} / \mathrm{mL})$ recovered the cells' original round shape. (C) The level of LDH release was measured using an LDH assay, and there were no significant differences in the LDH levels between the CGD polysaccharide groups and the LPS-only group. Mean \pm SEM $(n=3$ independent experiments). $\# P<0.05$, $\# \# \mathrm{P}<0.01$, and \#\#\#P<0.001, vs. the control group. ${ }^{* *} \mathrm{P}<0.01$ and ${ }^{* * *} \mathrm{P}<0.001$, vs. the LPS group. 
suppressed the expression of the pro-inflammatory cytokines IL-1 $\beta$, IL- 6 and TNF- $\alpha$. At the same time, the expression of IL-10, an antiinflammatory cytokine, was up-regulated.

CGD polysaccharide inhibited the MAPK/NF$\kappa B$ signaling pathways in RAW264.7 cells

NF- $\kappa \mathrm{B}$ and MAPKs are primary regulators of inflammatory responses, and activation of these pathways could stimulate the production of proinflammatory mediators including iNOS, IL-1 $\beta$, IL- 6 and TNF- $\alpha[10,11]$. As depicted in Fig. $3 \mathrm{~A}$ and Fig. 4, LPS triggered the phosphorylation of NF$\kappa \mathrm{B}$ p65 and increased its translocation from the cytoplasm to the nucleus, and it thereby induced the activation of the NF- $\kappa B$ signaling pathway. This process was significantly suppressed by CGD polysaccharide. The activation of NF- $\kappa B$ can be positively regulated by MAPK signaling molecules [12, 13]. Therefore, we also examined the phosphorylation levels of MAPK signaling molecules, comprising ERK1/2, JNK and p38, by western blotting. As shown in Fig. 3B, LPS stimulated the phosphorylation of p38, JNK and ERK1/2, and this process was significantly inhibited by CGD polysaccharide. However, the total protein levels of ERK1/2, JNK and p38were relatively constant in all groups.

CGD polysaccharide inhibited thePI3K/AKT/JNK and JAK/STAT signaling pathways in RAW264.7 cells

PI3K/AKT/JNK signaling mediates the inflammatory actions of LPS and modulates several downstream effectors, all of which eventually promote NF- $\mathrm{BB}$ activation $[14,15]$.

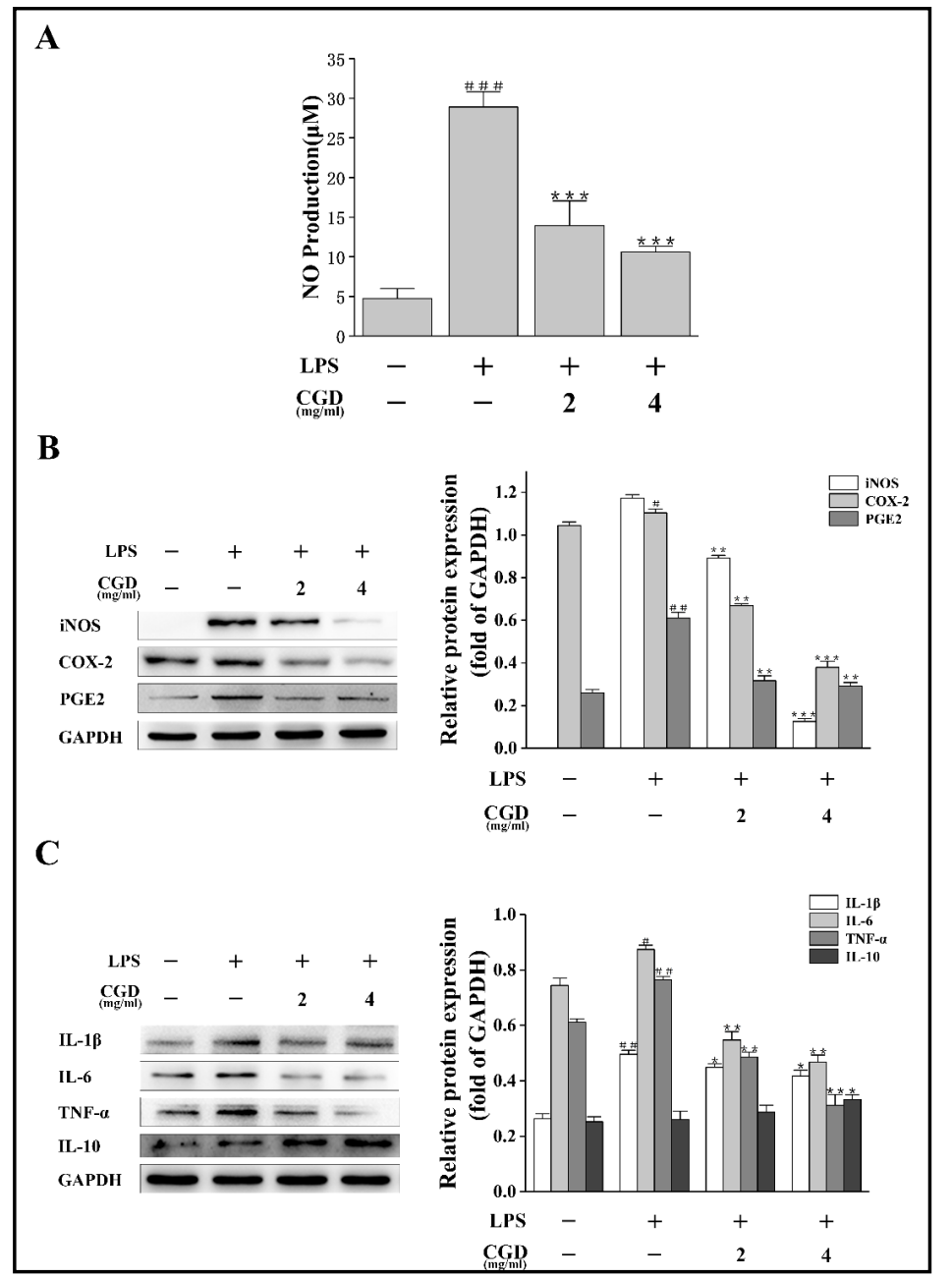

Fig. 2. The effect of CGD polysaccharide on the production of inflammatory mediators and cytokines in LPS-stimulated RAW 264.7 cells. Cells were pretreated separately with CGD polysaccharide (2 or $4 \mathrm{mg} / \mathrm{mL}$ ) for $2 \mathrm{~h}$, followed by LPS $(1 \mu \mathrm{g} / \mathrm{mL})$ stimulation for $24 \mathrm{~h}$. (A) The concentrations of NO were measured using the Griess reaction, and CGD polysaccharide significantly inhibited NO production. (B) and (C) The protein expressions of inflammatory mediators and cytokines were measured by western blotting, and CGD polysaccharide significantly inhibited LPS-induced expression of inflammatory mediators(PGE, iNOS and COX-2) and pro-inflammatory cytokines (TNF- $\alpha$, IL- 6 and IL-1 $\beta$ ), and it up-regulated the expression of the anti-inflammatory cytokine IL-10. Mean \pm SEM ( $\mathrm{n}=3$ independent experiments). $\# \mathrm{P}<0.05$, $\# \# \mathrm{P}<0.01$ and \#\#\#P<0.001 vs. the control group. ${ }^{*} \mathrm{P}<0.05$, ${ }^{* *} \mathrm{P}<0.01$ and $* * * \mathrm{P}<0.001$ vs. the LPS group. 
The activation of NF- $\mathrm{BB}$ can induce the production of cytokines, which might mediate inflammatory reactions through the JAK/STAT pathway [16], while LPS-stimulated activation of the JAK/STAT pathway is also very important for the production of cytokines via the PI3K/ JNK cascade [17]. Therefore, we analyzed the expression of multiple signaling molecules including PI3K, AKT, JNK and STAT3 by western blotting. As shown in Fig. 3B and Fig. 5, LPS up-regulated the expression of PI3K and stimulated the phosphorylation of AKT, JNK and STAT3. As expected, CGD polysaccharide significantly decreased PI3K expression and inhibited the activation of the PI3K/AKT/JNK and JAK/STAT signaling pathways. However, the total protein levels of AKT and STAT3 were relatively constant in all groups.

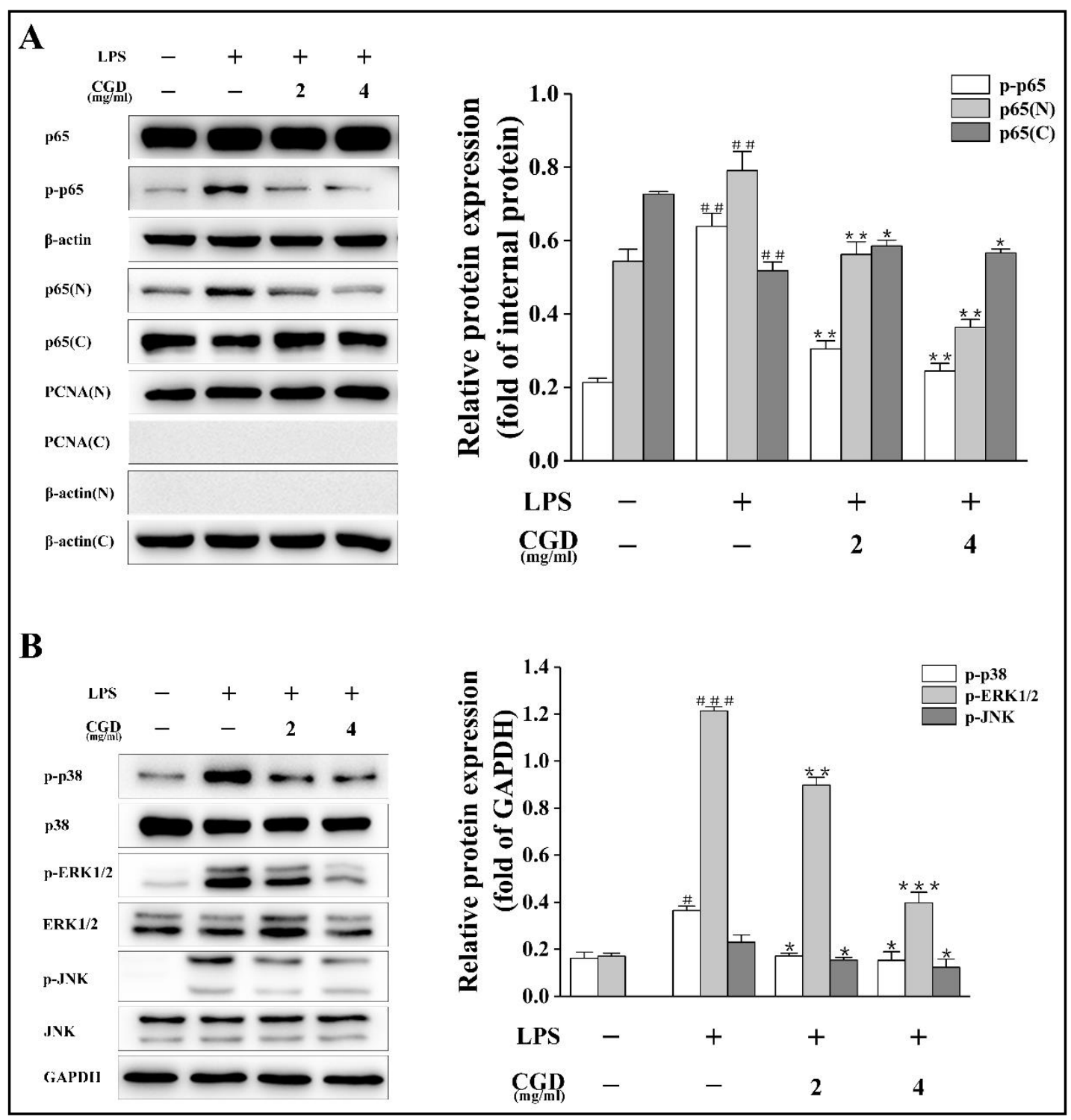

Fig. 3. The effect of CGD polysaccharide on the MAPK/NF- $\kappa B$ signaling pathway in LPS-stimulated RAW 264.7 cells. Cells were pretreated separately with CGD (2 or $4 \mathrm{mg} / \mathrm{mL}$ ) for $2 \mathrm{~h}$, followed by LPS (1 $1 \mu \mathrm{g} / \mathrm{mL})$ stimulation for $30 \mathrm{~min}(\mathrm{~A})$ or $1 \mathrm{~h}(\mathrm{~B})$, and the protein expressions were then measured by western blotting. CGD polysaccharide significantly suppressed the phosphorylation of NF- $\kappa B$ p65, p38, JNK and ERK1/2, and decreased the translocation of NF- $\mathrm{KB}$ p65 from the cytoplasm to the nucleus compared with the translocationin the LPS group. However, the total protein levels of NF- $\mathrm{B}$ p65, ERK1/2, JNK and p38 were relatively constant in all groups. Mean \pm SEM ( $\mathrm{n}=3$ independent experiments). \#P<0.05, \#\#P<0.01 and \#\#\#P<0.001 vs. the control group. ${ }^{*} \mathrm{P}<0.05,{ }^{* *} \mathrm{P}<0.01$ and ${ }^{* * *} \mathrm{P}<0.001$ vs. the LPS group. 


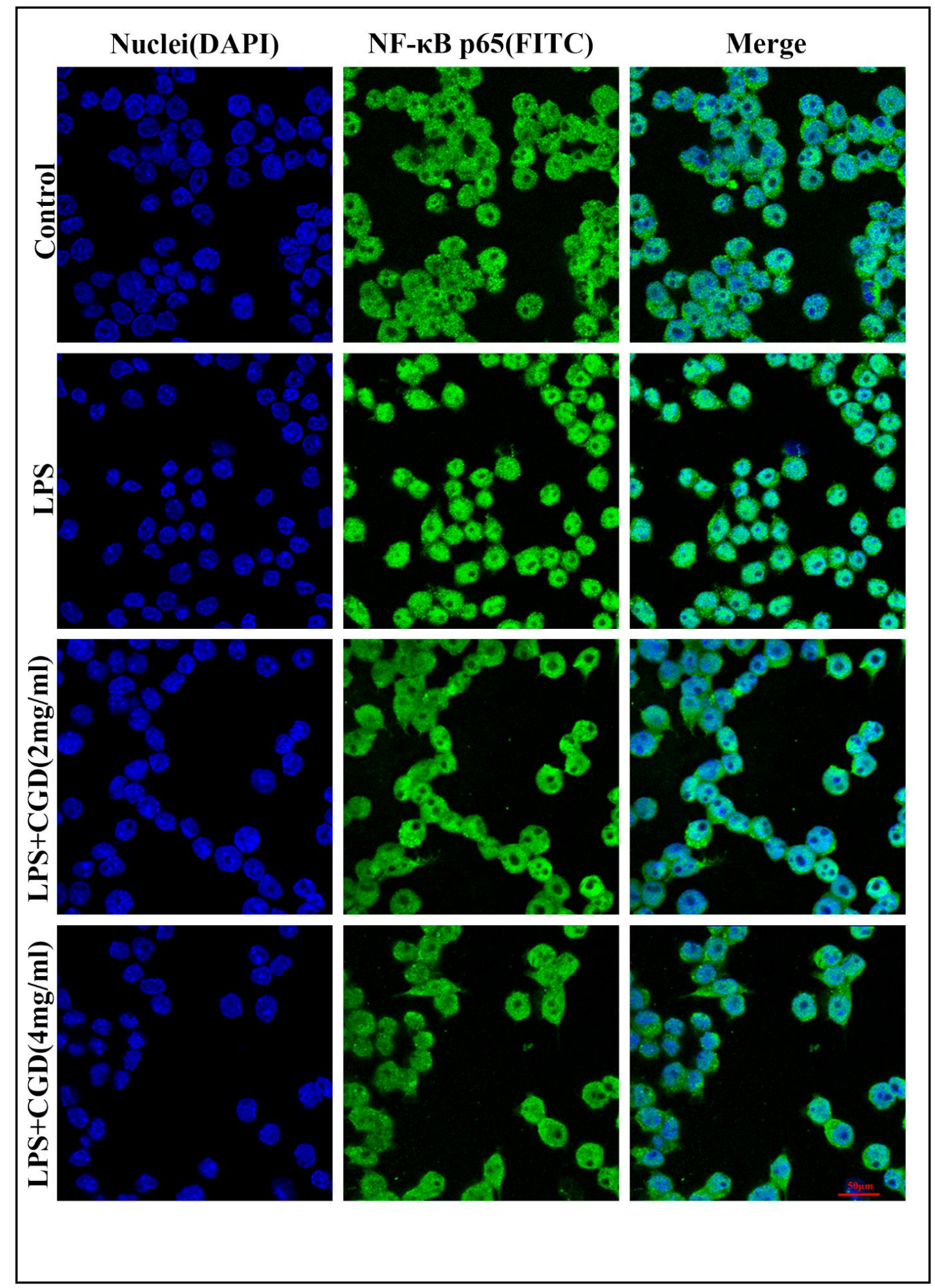

Fig. 4. The effect of CGD polysaccharide on the nuclear translocation of NF- $\kappa B$ p65 in LPS-stimulated

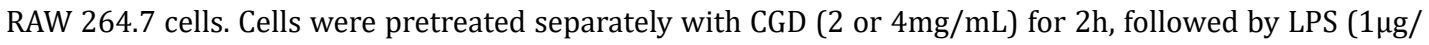
$\mathrm{mL}$ ) stimulation for $1 \mathrm{~h}$. NF- $\mathrm{\kappa B}$ p 65 was then detected by FITC-labeled immunostaining (green) and the nuclei were stained with DAPI (blue). Subsequently, the cells were viewed at a magnification $\times 600$. CGD polysaccharide significantly blocked NF- $\mathrm{B}$ p65 translocation from the cytoplasm to the nucleus compared with the translocation in the LPS group. 
Dai et al:: CGD Inhibits LPS-Induced Inflammation via Regulating the Signaling

Pathways

CGD polysaccharide enhanced the Nrf2/HO-1 signaling pathway in RAW264.7 cells

It has been demonstrated that Nrf2 blocks the expression of pro-inflammatory cytokines and inhibits inflammatory responses [18]. After translocation to the nucleus, Nrf2 initiates the transcription of genes encoding cytoprotective proteins. Among these proteins, HO-1 is the major effector and plays a vital role in anti-inflammation and anti-oxidation responses [19-21]. As shown in Fig. 6, CGD polysaccharide promoted the translocation of Nrf2 from the cytoplasm into the nucleus in LPS-stimulated macrophages and significantly increased the expression of HO-1.

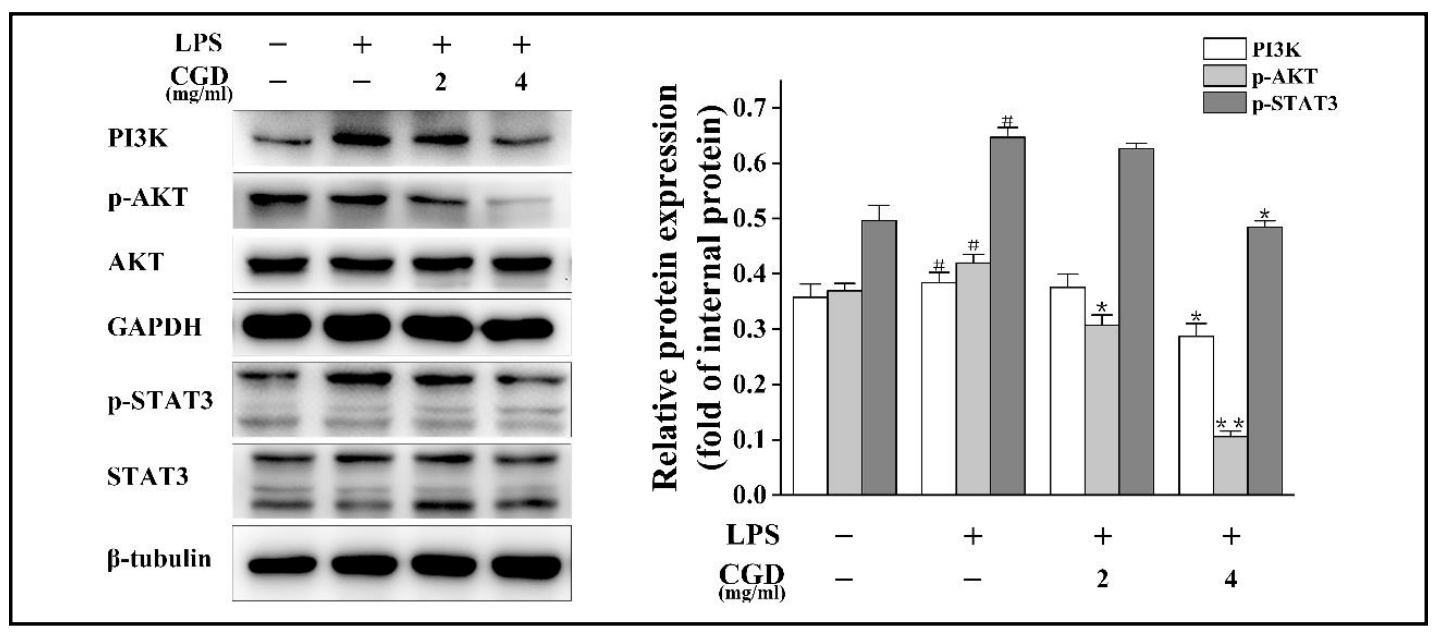

Fig. 5. The effect of CGD polysaccharide on the PI3K/AKT/JNK and JAK/STAT signaling pathways in LPSstimulated RAW 264.7 cells. Cells were pretreated separately with CGD (2 or $4 \mathrm{mg} / \mathrm{mL}$ ) for $2 \mathrm{~h}$, followed by LPS $(1 \mu \mathrm{g} / \mathrm{mL}$ ) stimulation for $30 \mathrm{~min}$ (for the PI3K, AKT and p-AKT experiments) or $4 \mathrm{~h}$ (for the STAT3 and p-STAT3 experiments). Subsequently, the protein expressions were measured by western blotting. CGD polysaccharide significantly decreased PI3K expression and inhibited the phosphorylation of AKT and STAT3. Mean \pm SEM ( $\mathrm{n}=3$ independent experiments). $\# \mathrm{P}<0.05$ vs. the control group. ${ }^{*} \mathrm{P}<0.05$ and ${ }^{* *} \mathrm{P}<0.01$ vs. the LPS group.

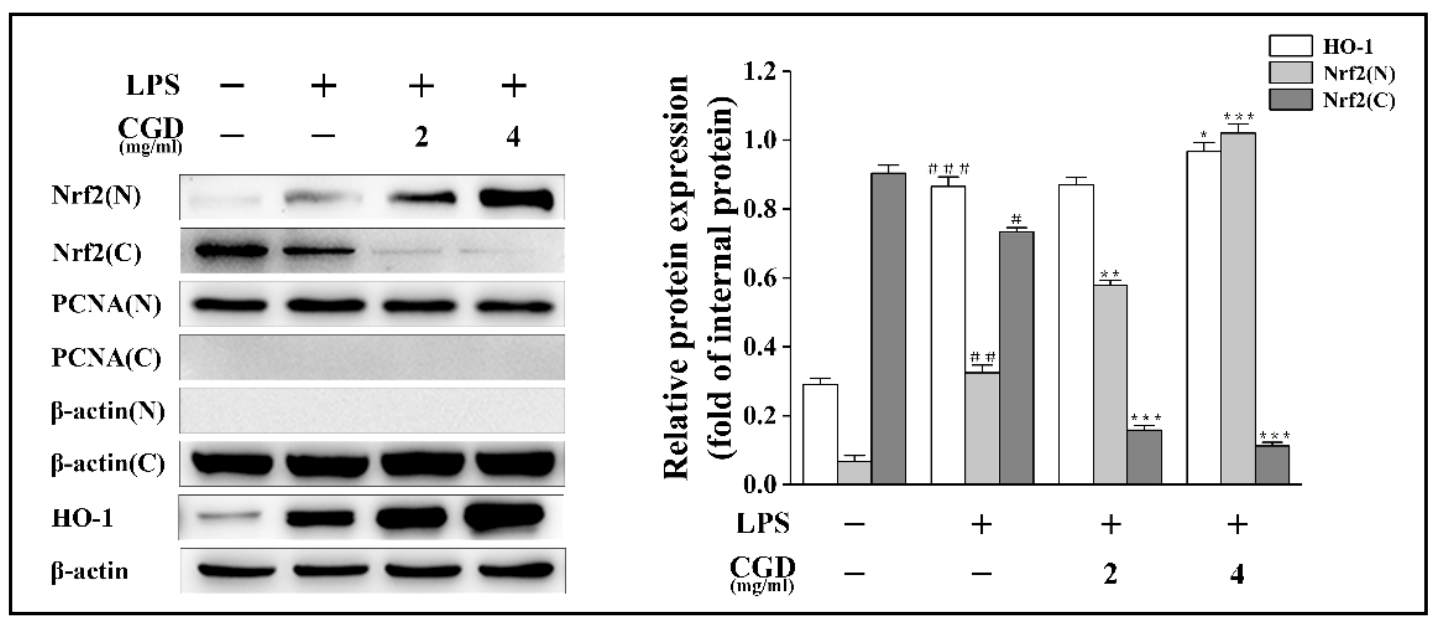

Fig. 6. The effect of CGD polysaccharide on the Nrf2/HO-1 signaling pathway in LPS-stimulated RAW 264.7 cells. Cells were pretreated separately with CGD $(2 \mathrm{or} 4 \mathrm{mg} / \mathrm{mL})$ for $2 \mathrm{~h}$, followed by LPS $(1 \mu \mathrm{g} / \mathrm{mL})$ stimulation for $1 \mathrm{~h}$ (for the Nrf2 experiment) or $24 \mathrm{~h}$ (for the HO-1 experiment). Subsequently, the protein expressions were measured by western blotting. CGD polysaccharide promoted the translocation of Nrf2 from the cytoplasm into the nucleus and significantly increased the expression of HO-1 in LPS-stimulated

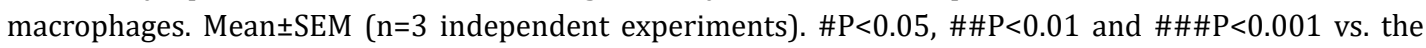
control group. ${ }^{*} \mathrm{P}<0.05,{ }^{* *} \mathrm{P}<0.01$ and ${ }^{* * *} \mathrm{P}<0.001$ vs. the LPS group. 


\section{Cellular Physiology Cell Physiol Biochem 2018;51:2523-2535

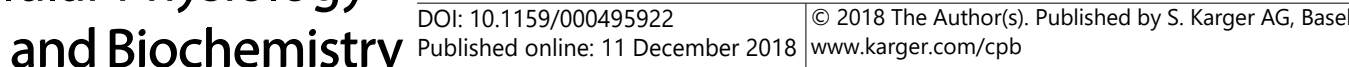 Dai et al.: CGD Inhibits LPS-Induced Inflammation via Regulating the Signaling Pathways}

\section{Discussion}

Inflammation plays significant roles in the development and progression of NCDs, including cancer, diabetes and cardiovascular diseases, which kill 41 million people annually, accounting for $71 \%$ of all deaths globally $[2,22]$. Therefore, the World Health Organization (WHO) Independent High-level Commission has called for urgent action to address these diseases, and anti-inflammatory agents are a promising strategy to alleviate and even cure these diseases.

Inflammation is a cascade reaction involving a large number of inflammatory mediators including NO, PGE, TNF- $\alpha$, IL-6,IL-1 $\beta$ and IL-10 [23-26].The production of NO and PGE $_{2}$ are directly regulated by iNOS and COX-2 [27]. In the present study, we found that CGD polysaccharide effectively inhibited LPS-induced production of $\mathrm{NO}$ and expression of $\mathrm{PGE}_{2}$ by reducing the expression of iNOS and COX-2. CGD polysaccharide also suppressed the expression of the pro-inflammatory cytokines TNF- $\alpha$, IL- 6 and IL-1 $\beta$, and up-regulated the expression of the anti-inflammatory cytokine IL-10.

It is well established that the expression of these inflammatory mediators is strictly controlled by the MAPK/NF- $\kappa \mathrm{B}, \mathrm{PI} 3 \mathrm{~K} / \mathrm{AKT} / \mathrm{JNK}$, JAK/STAT and Nrf2/HO-1 signaling pathways. In mammals, the NF- $\kappa B$ family comprises five structurally related proteins, RelA (p65), RelB, c-Rel, p105 (p50) and p100 (p52), forming heterodimers or homodimers through Rel homology domains. Under normal physiological states, NF- $\kappa \mathrm{B}$ is masked by the inhibitory I $\kappa$ B protein and sequestered in the cytosol. Upon exposure to inflammatory stimulants, such

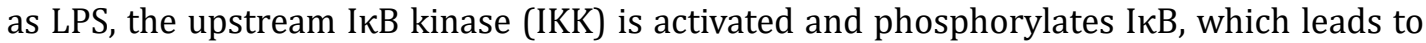
the degradation of I $\mathrm{KB}$. The cytosolic NF- $\kappa \mathrm{B}$ proteins are then transported into the nucleus. The translocation of the NF- $\mathrm{BB}$ p50-p65 dimer to the nucleus is the key step for its activation, which induces the transcription of various inflammatory genes, including those encoding iNOS and COX-2, as well as genes encoding inflammatory cytokines [28]. Over stimulation of NF- $\kappa B$ signaling contributes to the occurrence and development of certain NCDs including cancer and cardiovascular diseases [29]. Therefore, the NF- $\mathrm{kB}$ signaling pathway might be a promising target for the treatment of these diseases [30]. Interestingly, our results showed that CGD polysaccharide significantly inhibited the phosphorylation of NF- $\kappa \mathrm{B}$, as well as its translocation from the cytoplasm to the nucleus in LPS-stimulated RAW 264.7 cells.

It has been reported that the activation of NF- $\kappa B$ could be positively regulated by MAPK signaling pathways $[31,32]$. The MAPK family consists of serine/threonine protein kinases including p38, ERK1/2 and JNK. The classic MAPK cascade consists of three sequential intracellular protein kinase activation steps and is initiated when the first member, MAPK kinase kinase (MAPKKK), is activated upon exposure to inflammatory stimulants. It then phosphorylates MAPK kinase (MAPKK), which is followed by the activation of the MAPKs. Stimulation of the MAPK pathway eventually leads to the expression of various inflammatory mediators and the occurrence of inflammatory responses, which might contribute to the pathology of diverse human diseases including cancer and neurodegenerative disorders such as Alzheimer's disease [33-35]. Our results demonstrated that CGD polysaccharide could significantly inhibit MAPK signaling by decreasing the phosphorylation of MAPKs including JNK, ERK1/2and p38 in LPS-stimulated RAW 264.7 cells.

Other signaling pathways such as the PI3K/AKT/JNK and JAK/STAT pathways also participate in the regulation of NF- $\mathrm{BB}$ signaling. It has been demonstrated that activated phosphorylated AKT (p-AKT) significantly increase IKK $\alpha$ phosphorylation, which enhances the phosphorylation and degradation of IкB, thereby leading to the activation of NF- $\kappa B$ [36]. STAT signaling pathways are usually activated by JAKs, which result in the translocation of STATs into the nucleus where they regulate the transcription of certain cytokine genes. In particular, STAT3 is the major regulator of pro-inflammatory cytokine production in macrophages. Interestingly, direct LPS treatment did not lead to STAT activation, but some cytokines, such as IL-6, can activate STAT through LPS-induced NF- $\kappa B$ activation $[16,37,38]$. The data showed that CGD polysaccharide significantly inhibited PI3K/AKT phosphorylation 
and attenuated the activation of STAT3, which indicated that it might exertits antiinflammatory effects through the direct or indirect inhibition of the MAPK/ NF- $\mathrm{BB}, \quad \mathrm{PI} 3 \mathrm{~K} / \mathrm{AKT} / \mathrm{JNK}$ and JAK/STAT signaling pathways.

I $\mathrm{n} \mathrm{f} \mathrm{l} \mathrm{a} \mathrm{m} \mathrm{m}$ a t o r y responses are also negatively regulated by certain anti-inflammatory signaling pathways to maintain homeostasis. Accumulated evidence has indicated that $\mathrm{HO}-1$ can inhibit the production of NO, PGE ${ }_{2}$ IL-1 $\beta$, IL-6 and TNF- $\alpha$ in vitro and in vivo [39-41]. Nrf2, the major transcription factor for HO-1 expression, must translocate to the nucleus before it can stimulate HO-1 expression. Under normal conditions, Nrf2 binds to its negative regulator, Kelch-like ECH-associated protein 1 (Keap1), and is sequestered in the cytoplasm. Various stimuli, such as reactive oxygen (ROS), can liberate Nrf2 from Keap1, and Nrf2 then translocates into the nucleus and results in the production of HO-1 [39]. HO-1 and its products exert a series of beneficial effects via cytoprotective, anti-oxidant, anti-apoptotic, immunosuppressive, and anti-inflammatory activities. Some studies have demonstrated that HO-1 is closely associated with the pathogenesis of certain chronic inflammatory disorders, such as cancer and diabetes $[42,43]$. Here, we explored the potential mechanism of CGD polysaccharide regarding the Nrf2/HO-1 pathway. We found that CGD polysaccharide significantly promoted the translocation of Nrf2 from the cytoplasm into the nucleus and increased the expression of HO-1in LPS-stimulated RAW264.7 cells.

\section{Conclusion}

In summary, our results revealed that CGD polysaccharide could inhibit the production of the inflammatory mediators $\mathrm{NO}$ and $\mathrm{PGE}_{2}$ by reducing the expression of iNOS and COX-2, and it also suppressed the expression of pro-inflammatory cytokines and up-regulated the expression of an anti-inflammatory cytokine in LPS-stimulated RAW 264.7 macrophages. The anti-inflammatory mechanisms of CGD polysaccharide lie in its regulatory effects on the inflammatory signaling pathways MAPK/NF- $\kappa B$, PI3K/AKT/JNK, JAK/STAT and Nrf2/ HO-1 (Fig. 7). In addition, as a naturally produced drug, CGD polysaccharide did not display any cytotoxic effects, even at a high concentration. Therefore, CGD polysaccharide has the potential to be used as a relatively safe and effective drug as part of treatment for NCDs.

\section{KARGER}




\section{Cellular Physiology Cell Physiol Biochem 2018;51:2523-2535 and Biochemistry Published \begin{tabular}{l|l} 
DOI: 10.1159/000495922 & $\begin{array}{l}\text { (c) } 2018 \text { The Author(s). Published by S. Karger AG, Basel } \\
\text { www.karger.com/cpb }\end{array}$
\end{tabular} Dai et al.: CGD Inhibits LPS-Induced Inflammation via Regulating the Signaling Pathways}

\section{Acknowledgements}

LNS contributed conception and design of the study; BD,DW, NZ, ZC, NX, TM and LZ performed experiments and analyzed the data; BD and LNS wrote the manuscript; all authors contributed to manuscript revision, read and approved the submitted version. This research was funded by Nikken Sohonsha Corporation of Japan.

\section{Disclosure Statement}

The authors declare that the research was conducted in the absence of any commercial or financial relationships that could be construed as a potential conflict of interest.

\section{References}

1 Ashley NT, Weil ZM, Nelson RJ: Inflammation: Mechanisms, Costs, and Natural Variation. Annual Review of Ecology Evolution \& Systematics 2012;43:385-406.

2 Scrivo R, Vasile M, Bartosiewicz I, Valesini G: Inflammation as "common soil” of the multifactorial diseases. Autoimmun Rev 2011;10:369-374.

-3 Sostres C, Gargallo CJ, Arroyo MT, Lanas A: Adverse effects of non-steroidal anti-inflammatory drugs (NSAIDs, aspirin and coxibs) on upper gastrointestinal tract. Best Pract Res Clin Gastroenterol 2010;24:121-132.

4 Schacke H, Docke WD, Asadullah K: Mechanisms involved in the side effects of glucocorticoids. Pharmacol Ther 2002;96:23-43.

5 Wang W, Wang SX, Guan HS: The antiviral activities and mechanisms of marine polysaccharides: an overview. Mar Drugs 2012;10:2795-2816.

6 Guiry, M. D. G., G. M: Coccomyxa gloeobotrydiformis Reisigl. Available from: http://www.algaebase.org/ search/species/detail/?species_id=H72dc4e4819414c40. [cited 201805 June ].

7 Sun L, Jin Y, Dong L, Sumi R, Jahan R, Li Z: The neuroprotective effects of Coccomyxa gloeobotrydiformis on the ischemic stroke in a rat model. Int J Biol Sci 2013;9:811-817.

-8 Sun L, Jin Y, Dong L, Sui HJ, Sumi R, Jahan R, Hu D, Li Z: Coccomyxa Gloeobotrydiformis Improves Learning and Memory in Intrinsic Aging Rats. Int J Biol Sci 2015;11:825-832.

-9 Zheng N, Ding X, Wei D, Dai B, Zheng L, Sumi R, Hu D, Jahane R, Sun L: Therapeutic Effects of Coccomyxagloeobotrydiformis on the Metabolic Syndrome in Rats. Cell Physiol Biochem 2018;48:15191529.

10 Yoon YK, Woo HJ, Kim Y: Orostachys japonicus Inhibits Expression of the TLR4, NOD2, iNOS, and COX-2 Genes in LPS-Stimulated Human PMA-Differentiated THP-1 Cells by Inhibiting NF-kappaB and MAPK Activation. Evid Based Complement Alternat Med 2015;2015:682019.

11 Endale M, Park SC, Kim S, Kim SH, Yang Y, Cho JY, Rhee MH: Quercetin disrupts tyrosine-phosphorylated phosphatidylinositol 3-kinase and myeloid differentiation factor-88 association, and inhibits MAPK/AP-1 and IKK/NF-kappaB-induced inflammatory mediators production in RAW 264.7 cells. Immunobiology 2013;218:1452-1467.

12 Karunakaran S, Ravindranath V: Activation of p38 MAPK in the substantia nigra leads to nuclear translocation of NF-kappaB in MPTP-treated mice: implication in Parkinson's disease. J Neurochem 2009;109:1791-1799.

13 Lee SM, Kim EJ, Suk K, Lee WH: Stimulation of Fas (CD95) induces production of pro-inflammatory mediators through ERK/JNK-dependent activation of NF-kappaB in THP-1 cells. Cell Immunol 2011;271:157-162.

14 Guo C, Yang L, Luo J, Zhang C, Xia Y, Ma T, Kong L: Sophoraflavanone G from Sophora alopecuroides inhibits lipopolysaccharide-induced inflammation in RAW264.7 cells by targeting PI3K/Akt, JAK/STAT and Nrf2/ HO-1 pathways. Int Immunopharmacol 2016;38:349-356.

15 Chu AJ: Antagonism by bioactive polyphenols against inflammation: a systematic view. Inflamm Allergy Drug Targets 2014;13:34-64. 


\section{Cellular Physiology Cell Physiol Biochem 2018;51:2523-2535

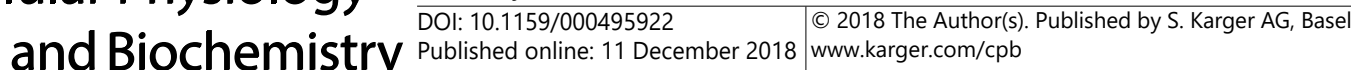

Dai et al:: CGD Inhibits LPS-Induced Inflammation via Regulating the Signaling

Pathways

16 Fujihara M, Muroi M, Tanamoto K, Suzuki T, Azuma H, Ikeda H: Molecular mechanisms of macrophage activation and deactivation by lipopolysaccharide: roles of the receptor complex. Pharmacol Ther 2003;100:171-194.

17 Okugawa S, Ota Y, Kitazawa T, Nakayama K, Yanagimoto S, Tsukada K, Kawada M, Kimura S: Janus kinase 2 is involved in lipopolysaccharide-induced activation of macrophages. Am J Physiol Cell Physiol 2003;285:C399-408.

18 Kobayashi EH, Suzuki T, Funayama R, Nagashima T, Hayashi M, Sekine H, Tanaka N, Moriguchi T, Motohashi H, Nakayama K, Yamamoto M: Nrf2 suppresses macrophage inflammatory response by blocking proinflammatory cytokine transcription. Nat Commun 2016;7:11624.

19 Shie PH, Wang SY, Lay HL, Huang GJ: 4, 7-Dimethoxy-5-methyl-1, 3-benzodioxole from Antrodia camphorata inhibits LPS-induced inflammation via suppression of NF-kappaB and induction HO-1 in RAW264.7 cells. Int Immunopharmacol 2016;31:186-194.

-20 Zhang B, Yan L, Zhou P, Dong Z, Feng S, Liu K, Gong Z: CHP1002, a novel andrographolide derivative, inhibits pro-inflammatory inducible nitric oxide synthase and cyclooxygenase-2 expressions in RAW264.7 macrophages via up-regulation of heme oxygenase-1 expression. Int Immunopharmacol 2013;15:289-295.

21 Wei W, Shurui C, Zipeng Z, Hongliang D, Hongyu W, Yuanlong L, Kang Z, Zhaoliang S, Yue G, Chang L, Mei X: Aspirin suppresses neuronal apoptosis, reduces tissue inflammation, and restrains astrocyte activation by activating the Nrf2/HO-1 signaling pathway. Neuroreport 2018;29:524-531.

22 (NCDs), W.H.O.W.I.H.-l.C.o.N.D.: Commission calls for urgent action against chronic diseases. Available from: http://www.who.int/zh/news-room/01-06-2018-commission-calls-for-urgent-action-against-chronicdiseases [cited 201822 June]..

23 Zhou LT, Wang KJ, Li L, Li H, Geng M: Pinocembrin inhibits lipopolysaccharide-induced inflammatory mediators production in BV2 microglial cells through suppression of PI3K/Akt/NF-kappaB pathway. Eur J Pharmacol 2015;761:211-216.

24 Do H, Pyo S, Sohn EH: Suppression of iNOS expression by fucoidan is mediated by regulation of p38 MAPK, JAK/STAT, AP-1 and IRF-1, and depends on up-regulation of scavenger receptor B1 expression in TNFalpha- and IFN-gamma-stimulated C6 glioma cells. J Nutr Biochem 2010;21:671-679.

25 Li C, Gao Y, Xing Y, Zhu H, Shen J, Tian J: Fucoidan, a sulfated polysaccharide from brown algae, against myocardial ischemia-reperfusion injury in rats via regulating the inflammation response. Food Chem Toxicol 2011;49:2090-2095.

26 Choi JI, Raghavendran HR, Sung NY, Kim JH, Chun BS, Ahn DH, Choi HS, Kang KW, Lee JW: Effect of fucoidan on aspirin-induced stomach ulceration in rats. Chem Biol Interact 2010;183:249-254.

27 Sanjeewa KK, Fernando IP, Kim EA, Ahn G, Jee Y, Jeon YJ: Anti-inflammatory activity of a sulfated polysaccharide isolated from an enzymatic digest of brown seaweed Sargassum horneri in RAW 264.7 cells. Nutr Res Pract 2017;11:3-10.

28 Zhao J, Li X, McGowan S, Niedernhofer LJ, Robbins PD: NF-kappaB activation with aging: characterization and therapeutic inhibition. Methods Mol Biol 2015;1280:543-557.

-29 Park MH, Hong JT: Roles of NF-kappaB in Cancer and Inflammatory Diseases and Their Therapeutic Approaches. Cells 2016;5:15.

-30 Viatour P, Merville MP, Bours V, Chariot A: Phosphorylation of NF-kappaB and IkappaB proteins: implications in cancer and inflammation. Trends Biochem Sci 2005;30:43-52.

-31 Aga M, Watters JJ, Pfeiffer ZA, Wiepz GJ, Sommer JA, Bertics PJ: Evidence for nucleotide receptor modulation of cross talk between MAP kinase and NF-kappa B signaling pathways in murine RAW 264.7 macrophages. Am J Physiol Cell Physiol 2004;286:C923-930.

-32 DeFranco AL, Hambleton J, McMahon M, Weinstein SL: Examination of the role of MAP kinase in the response of macrophages to lipopolysaccharide. Prog Clin Biol Res 1995;392:407-420.

-33 Johnson GL, Lapadat R: Mitogen-activated protein kinase pathways mediated by ERK, JNK, and p38 protein kinases. Science 2002;298:1911-1912.

-34 Weinstein SL, Sanghera JS, Lemke K, DeFranco AL, Pelech SL: Bacterial lipopolysaccharide induces tyrosine phosphorylation and activation of mitogen-activated protein kinases in macrophages. J Biol Chem 1992;267:14955-14962.

-35 Kim EK, Choi EJ: Compromised MAPK signaling in human diseases: an update. Arch Toxicol 2015;89:867882. 


\section{Cellular Physiology and Biochemistry}

Pathways

-36 Ozes ON, Mayo LD, Gustin JA, Pfeffer SR, Pfeffer LM, Donner DB: NF-kappaB activation by tumour necrosis factor requires the Akt serine-threonine kinase. Nature 1999;401:82-85.

37 Severgnini M, Takahashi S, Rozo LM, Homer RJ, Kuhn C, Jhung JW, Perides G, Steer M, Hassoun PM, Fanburg BL, Cochran BH, Simon AR: Activation of the STAT pathway in acute lung injury. Am J Physiol Lung Cell Mol Physiol 2004;286:L1282-1292.

-38 Samavati L, Rastogi R, Du W, Huttemann M, Fite A, Franchi L: STAT3 tyrosine phosphorylation is critical for interleukin 1 beta and interleukin- 6 production in response to lipopolysaccharide and live bacteria. Mol Immunol 2009;46:1867-1877.

39 Paine A, Eiz-Vesper B, Blasczyk R, Immenschuh S: Signaling to heme oxygenase-1 and its anti-inflammatory therapeutic potential. Biochem Pharmacol 2010;80:1895-1903.

40 Choo YY, Lee S, Nguyen PH, Lee W, Woo MH, Min BS, Lee JH: Caffeoylglycolic acid methyl ester, a major constituent of sorghum, exhibits anti-inflammatory activity via the Nrf2/heme oxygenase-1 pathway. Rsc Advances 2015;5:17786-17796.

41 Son Y, Chung HT, Pae HO: Differential effects of resveratrol and its natural analogs, piceatannol and 3, 5,4'-trans-trimethoxystilbene, on anti-inflammatory heme oxigenase-1 expression in RAW264.7 macrophages. Biofactors 2014;40:138-145.

42 Loboda A, Damulewicz M, Pyza E, Jozkowicz A, Dulak J: Role of Nrf2/HO-1 system in development, oxidative stress response and diseases: an evolutionarily conserved mechanism. Cell Mol Life Sci 2016;73:3221-3247.

43 Li BZ, Guo B, Zhang HY, Liu J, Tao SS, Pan HF, Ye DQ: Therapeutic potential of HO-1 in autoimmune diseases. Inflammation 2014;37:1779-1788. 